\title{
Suppressor of Cytokine Signaling 1 is Involved in Gene Regulation Which Controls the Survival of Ly6Clow Monocytes in Mice
}

\author{
Jutta Schuett ${ }^{\mathrm{a}} \quad$ Julian Kreutz ${ }^{\mathrm{a}} \quad$ Karsten Grote $^{\mathrm{a}} \quad$ Ann-Kathrin Vlacila \\ Harald Schuett $^{\mathrm{a}}$ Raghav Oberoi ${ }^{\mathrm{a}}$ Andreas Schmid ${ }^{\mathrm{b}}$ Anika Witten ${ }^{\mathrm{c}}$ \\ Monika Stollc,d Bernhard Schieffer ${ }^{a}$ Frank Rühle ${ }^{c}$
}

\begin{abstract}
aDepartment of Cardiology and Angiology, Philipps-University Marburg, Marburg, Germany, 'Department of Internal Medicine III, Giessen University Hospital, Giessen, Germany, 'Department of Genetic Epidemiology, Institute of Human Genetics, University of Münster, Münster, Germany, dDepartment of Biochemistry, Genetic Epidemiology and Statistical Genetics, CARIM School for Cardiovascular Diseases, Maastricht Center for Systems Biology (MaCSBio), Maastricht University, Maastricht, The Netherlands
\end{abstract}

\section{Key Words}

Ly6C $\cdot$ Monocytes $\cdot$ Suppressor of cytokine signaling $1 \cdot \mathrm{CX} 3 \mathrm{C}$ chemokine receptor $1 \cdot$ Colony stimulating factor 1 receptor $\cdot$ Peroxisome proliferator-activated receptor gamma $\cdot \mathrm{Nr} 4 \mathrm{a} 1 \cdot$ ETS-domain $•$ mRNA microarray

\begin{abstract}
Background/Aims: Inflammatory processes are controlled by the fine-tuned balance of monocyte subsets. In mice, different subsets of monocytes can be distinguished by the expression of Ly6C that is highly expressed on inflammatory monocytes (Ly6C high) and to a lesser extent on patrolling monocytes (Ly6Clow). Our previous study revealed an accumulation of Ly6Chigh monocytes in atherosclerotic-prone mice bearing a deficiency in suppressor of cytokine signaling (SOCS)-1 leading to an increased atherosclerotic burden. To decipher the underlying mechanisms, we performed a genome-wide analysis of SOCS-1-dependent gene regulation in Ly6Chigh and Ly6Clow monocytes. Methods: In monocyte subsets from SOCS-1competent and -deficient mice differentially regulated genes were identified using an Illumina mRNA microarray (45,200 transcripts), which were randomly validated by qPCR. Principal component analysis was performed to further characterize mRNA profiles in monocyte subsets. To unravel potential regulatory mechanisms behind the differential mRNA expression, in silico analysis of a transcription factor (TF) network correlating with SOCS-1-dependent mRNA expression was carried out and combined with a weighted correlation network analysis (WGCNA). Results: mRNA analysis in monocyte subsets revealed 46 differentially regulated


genes by 2-fold or more. Principal component analysis illustrated a distinct separation of mRNA profiles in monocyte subsets from SOCS-1-deficient mice. Notably, two cell surface receptors crucially involved in the determination of monocyte differentiation and survival, C-X3-C chemokine receptor 1 (CX3CR1) and colony stimulating factor 1 receptor (CSF1R), were identified to be regulated by SOCS-1. Moreover, in silico analysis of a TF network in combination with the WGCNA revealed genes coding for PPAR- $\gamma$, NUR77 and several ETSdomain proteins that act as pivotal inflammatory regulators. Conclusion: Our study reveals that SOCS-1 is implicated in a TF network regulating the expression of central transcription factors like PPAR $-\gamma$ and NUR77 thereby influencing the expression of CX3CR1 and CSF1R that are known to be pivotal for the survival of Ly6Clow monocytes.

(C) 2019 The Author(s). Published by Cell Physiol Biochem Press GmbH\&Co. KG

\section{Introduction}

Cardiovascular diseases are the leading cause of morbidity and mortality worldwide [1]. They are primarily caused by atherosclerosis, a chronic inflammatory disease of arteries. Monocytes are pivotal in inflammatory processes and are the main drivers of atherogenesis $[2,3]$. They can be divided into different subsets in men as well as in mice. Murine monocytes are characterized by their expression of CD11b and CD115 which is also known as colony stimulating factor 1 receptor (CSF1R). Furthermore, they exhibit differential expression patterns of C-C chemokine receptor 2 (CCR2), C-X3-C motif chemokine receptor 1 (CX3CR1) and Ly6C. While inflammatory monocytes express high levels of CCR2 and Ly6C (Ly6C ${ }^{\text {high }}$ monocytes), patrolling monocytes express only low levels of Ly6C (Ly6 ${ }^{\text {low }}$ monocytes) but high levels of CX3CR1 [4,5]. The development of Ly6C ${ }^{\text {low }}$ monocytes is not yet clearly understood. Generally, in adults monocytes develop in the bone marrow from monocyte progenitor cells. Under steady state conditions, Ly6C $\mathrm{C}^{\text {high }}$ monocytes are released from the bone marrow to peripheral blood where they can convert into Ly6 $\mathrm{C}^{\text {low }}$ monocytes that have the unique ability of patrolling along the vasculature and surveying endothelial integrity $[6,7]$. However, there might also exist alternative ways for Ly6C $\mathrm{C}^{\text {low }}$ monocytes to develop independently of the Ly6C $\mathrm{C}^{\text {high }}$ population [8]. In this context, the transcription factor NUR77 that is encoded by the gene of nuclear receptor subfamily 4 group A member 1 (Nr4a1), has been proven to be indispensable for the development and survival of Ly $6 \mathrm{C}^{\text {low }}$ monocytes from myeloid progenitors in the bone marrow [9]. During inflammatory processes, C-C chemokine ligand 2 mediates recruitment of Ly6 ${ }^{\text {high }}$ monocytes to the sites of action which invade the affected tissue and differentiate mainly into pro-inflammatory M1 macrophages [10]. Additionally, a third monocyte subset has been suggested that is characterized by an intermediate expression of Ly6C (Ly6 $\mathrm{C}^{\text {int }}$ monocytes), a rather pro-inflammatory behavior and the susceptibility to differentiate to dendritic cells [11]. However, it still has to be clarified if this cell population is just a transition state from converting Ly6C ${ }^{\text {high }}$ into Ly $6 C^{\text {low }}$ monocytes or if it represents an independent subpopulation.

The suppressor of cytokine signaling (SOCS)-1 is a negative feedback loop regulator that acts on several sites of the JAK/STAT pathway. Besides its inhibitory effect on type I interferon (IFN) signaling, SOCS-1 also limits toll-like receptor 4 activation and thereby leads to the transcriptional inhibition of multiple pro-inflammatory cytokines [12,13]. SOCS-1 knockout mice exhibit growth retardation and die within the first three weeks from an uncontrolled IFN $\gamma$ secretion of T1-helper cells [14]. The overshooting release of IFN- $\gamma$ triggered by T cell alterations in Socs-1 $1^{-/-}$mice can be overcome by an additional deletion of the recombination of activation gene $2(\mathrm{Rag} 2)$ which results in the eradication of T and B cells and consequently in the survival of Socs-1-1- $\mathrm{Rag}^{-/-}$mice [15]. In respect to chronic inflammatory diseases like atherosclerosis, high expression of SOCS-1 has been detected in vascular smooth muscle cells and macrophages of murine and human atherosclerotic lesions $[16,17]$. While Socs-1 gene delivery diminishes the onset and progression of plaque development in $A p o E^{-/-}$mice by attenuating STAT activation and expression of STAT-dependent genes $[16,18]$, SOCS-

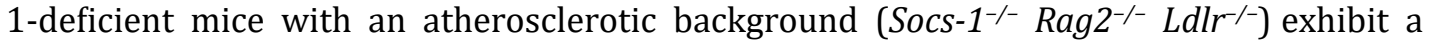




\section{Cellular Physiology Cell Physiol Biochem 2019;52:336-353 \\ \begin{tabular}{ll|l} 
and Biochemistry & $\begin{array}{l}\text { DOl: 10.33594/000000024 } \\
\text { Published online: } 28 \text { February } 2019\end{array}$ & $\begin{array}{l}\text { C 2019 The Author(s). Published by } \\
\text { Cell Physiol Biochem Press GmbH\&Co. KG }\end{array}$ \\
\cline { 2 - 3 } &
\end{tabular} \\ Schuett et al.: SOCS-1-Dependent Gene Regulation}

pronounced plaque formation. Augmented atherogenesis is accompanied by an excessive appearance of inflammatory M1 macrophages, Ly6C ${ }^{\text {high }}$ monocytes and neutrophils, suggesting an anti-inflammatory and potentially athero-protective effect of SOCS-1 [19].

In order to elucidate the regulatory mechanisms behind the anti-inflammatory effect of SOCS-1 in the murine model of chronic inflammation, we performed an mRNA microarray of Ly6 $\mathrm{C}^{\text {high }}$ and Ly $6 \mathrm{C}^{\text {low }}$ monocyte subsets from SOCS-1-competent and SOCS-1-deficient mice bearing an atherosclerotic background.

\section{Materials and Methods}

\section{Mice}

This study was carried out in accordance with the recommendations of the governmental animal ethics committee and performed according to the EU Directive 2010/63/EU for animal experiments and the guidelines of the Federation of European Animal Science Associations. The protocol was approved by the governmental animal ethics committee (MR 20/37 G63/2016). Socs-1 ${ }^{-/-}$Rag2 $^{-/-}$Ldlr $^{/-}\left(\mathrm{SRL}^{-/-}\right.$), Socs-1 1/+ $^{+/}$ $\mathrm{Rag2}^{-/-} \mathrm{Ldlr}^{-/-}\left(\mathrm{RL}^{-/-}\right)$and Socs-1//+ $\mathrm{Rag2}^{+/+} \mathrm{Ldlr}^{\text {/- }^{-}}\left(\mathrm{L}^{-/-}\right)$male mice on a C57BL/6J background were bred and maintained in the Central Animal Facility at the Philipps-University Marburg. At the age of 8 to 10 weeks, mice were killed by cervical dislocation for bone marrow isolation.

\section{Cells}

For the isolation of bone marrow-derived monocytes, femurs and tibiae were taken from $\mathrm{SRL}^{-/-}, \mathrm{RL}^{-/-}$ and $\mathrm{L}^{-/-}$mice, bone marrow was flushed out with RPMI-1640 supplemented with GlutaMAX ${ }^{\mathrm{TM}}$ (ThermoFisher Scientific, Carlsbad, CA) and 1\% fetal calf serum (FCS, PAN-Biotech, Aidenbach, Germany). After red blood cell lysis, cells were filtered through a $70 \mu \mathrm{m}$ cell strainer (greiner bio-one, Frickenhausen, Germany) to obtain a uniform single-cell suspension.

\section{Chemicals and antibodies}

Antibodies for flow cytometry and cell sorting against murine CD16/CD32, CD3e, CD11b, CD19, CD49b, CD117, NK1.1 and Ly6C were obtained from eBioscience (San Diego, CA). The antibody against Ly6G was purchased from BD Biosciences (Heidelberg, Germany). 4',6-diamidino-2-phenylindole (DAPI) was obtained from Sigma-Aldrich (Munich, Germany).

\section{Flow cytometry and cell sorting}

For the fluorescence-activated cell sorting (FACS) analysis of monocyte subsets, bone marrow was isolated from femurs and tibiae of $\mathrm{SRL}^{-/}, \mathrm{RL}^{-/-}$and $\mathrm{L}^{-/-}$mice as described above. After appropriate filtration, cell suspension was resuspended in PBS containing 2\% FCS and 0.2\% EDTA and blocking of Fc receptors was performed using anti-mouse CD16/CD32 monoclonal antibody. Cells were stained for 30 min on ice with anti-mouse CD3e (PE, 135-2C11, T cell marker), CD11b (Alexa488, M1/70, monocytic marker), CD19 (PE, eBio1DE, B cell marker), CD49b (PE, DX5, NK cell marker), CD117 (PE, 2B8, mast/stem cell marker), Ly6C (PerCP-Cy5.5, HK1.4, subset differentiation marker), Ly6G (PE, 1A8, granulocyte marker) and NK1.1 (PE, PK136, NK cell marker). DAPI was added to identify dead cells shortly before measurements. Monocytes were sorted using a MoFlo Legacy cell sorter from Beckman Coulter (Krefeld, Germany) and analyzed using FlowJo software version 10 (Tree Star Inc., Ashland, OR). Data were presented as mean with standard error of the mean (SEM). Data were compared using one-way ANOVA followed by Tukey multiple comparison test (GraphPad Prism, version 6.05, GraphPad Software, San Diego, CA). P-value of less than 0.05 was considered statistically significant. Numbers of replicated experiments are indicated in the figure legend.

\section{mRNA Microarray Analysis}

After separation of Ly6 $\mathrm{C}^{\text {high }}$ and Ly6 $\mathrm{C}^{\text {low }}$ monocyte subsets from six mice of each investigated genotype $\left(\mathrm{SRL}^{-/-}, \mathrm{RL}^{-/-}\right.$and $\mathrm{L}^{-/-}$) by FACS sorting, total RNA of overall 36 samples was isolated using RNeasy mini kit (Qiagen, Hilden, Germany). RNA purity and concentration were determined by NanoDrop 1000 spectrophotometer (ThermoFisher Scientific). To increase RNA concentrations, eluates were evaporated for 


\section{Cellular Physiology Cell Physiol Biochem 2019;52:336-353 \\ \begin{tabular}{ll|ll} 
and Biochemistry & $\begin{array}{l}\text { DOl: 10.33594/000000024 } \\
\text { Published online: } 28 \text { February } 2019\end{array}$ & $\begin{array}{l}\text { O } 2019 \text { The Author(s). Published by } \\
\text { Cell Physiol Biochem Press GmbH\&Co. KG }\end{array}$ \\
\cline { 2 - 3 } & Scher
\end{tabular} \\ Schuett et al.: SOCS-1-Dependent Gene Regulation}

$18 \mathrm{~min}$ in a SpeedVac system (von Keutz, Reiskirchen, Germany) until a final volume of $3 \mu \mathrm{L}$ was achieved. RNA integrity was subsequently analyzed using the Agilent RNA 6000 Nano total RNA kit and an Agilent 2000 Bioanalyzer system (Agilent Technologies, Waldbronn, Germany). Only RNA samples with a RNA integrity number (RIN) of 8 or higher were used for further microarray experiments. Therefore, RNA was transcribed into cDNA with SuperScript ${ }^{\text {ti }}$ III Reverse Transcriptase (ThermoFisher Scientific) and biotinaRNA was subsequently made using the TargetAmp-Nano Labeling kit for Illumina Expression BeadChip (Epicentre, Madison, WI).

Biotin-aRNA was purified using the RNeasy MinElute Cleanup kit from Qiagen and hybridized to Illumina Mouse WG-6 v2.0 expression BeadChips (illumina, San Diego, CA) with 6 replicates per group. Arrays were scanned on an Illumina BeadArray Reader and were analyzed using Illumina GenomeStudio software version 2011.1. Quality control was applied using the internal quality control probes as recommended by the manufacturer. Two replicates from SRL ${ }^{-/-}$Ly6C low and one replicate from $\mathrm{RL}^{-/-} \mathrm{Ly}_{6} \mathrm{C}^{\text {low }}$ monocyte subset group were removed during quality control. Microarray expression data were quantile normalized and the expressed gene targets were identified applying a detection p-value threshold of 0.05. Differentially expressed genes between sample groups were identified by Illumina Custom error model with false discovery rate (FDR) correction. Genes with a corrected differential expression p-value $<0.05$ and a fold change $>2$ or $<0.5$ were considered significantly regulated. All data are MIAME compliant; Microarray data have been deposited in the Gene Expression Omnibus database under the accession no. GSE103705.

\section{Principal Component Analysis}

The R-package pcaGoPromoter was used for principal component analysis of normalized and log2transformed gene expression data as previously described [42]. The first two principal components covering $26 \%$ of the variance of the dataset were visualized in the according PCA plot.

\section{Quantitative real-time polymerase chain reaction ( $q P C R$ )}

To validate gene expression profiles from the microarray, total RNA was isolated using RNeasy mini kit (Qiagen) and reverse-transcribed with SuperScript reverse transcriptase kit (Applied Biosystems, Darmstadt, Germany). Real-time PCR was performed in duplicates in a total volume of $20 \mu \mathrm{L}$ using Power SYBR $®$ green PCR master mixture (Applied Biosystems) on a Step OnePlus Real-Time PCR system (Applied Biosystems) in 96-well PCR plates. Real-time PCR was performed with an initial denaturation step at $95^{\circ} \mathrm{C}$ for $10 \mathrm{~min}$ followed by $40 \mathrm{PCR}$ cycles consisting of $95^{\circ} \mathrm{C}$ for $15 \mathrm{~s}, 60^{\circ} \mathrm{C}$ for $1 \mathrm{~min}$ and $72^{\circ} \mathrm{C}$ for $1 \mathrm{~min}$, and SYBR green fluorescence emission was monitored after each cycle. For normalization, expression of hypoxanthine phosphoribosyltransferase 1 (Hprt1) was determined in duplicates. Fold change with respect to control was calculated using the $2^{-\triangle \Delta C T}$ method. Data is presented as mean with standard error of the mean (SEM). Data were compared using one-way ANOVA followed by Dunnett's multiple comparison test (GraphPad Prism, version 6.05). P-value $<0.05$ was considered statistically significant. Numbers of replicated experiments are indicated in the figure legend. PCR primers were obtained from TIB MOLBIOL (Berlin, Germany) and primer sequences were as follows: ApoE forward: 5'-GCC GTG CTG TTG GTC AC-3', ApoE reverse: 5'-AAG CCT TTA CTT CCG TCA TAG TG-3', Csf1r forward: 5'-TCC ACC GGG ACG TAG CA-3', Csf1r reverse: 5'-CCA GTC CAA AGT CCC CAA TCT-3', Cx3cr1 forward: 5'-CAG CAT CGA CCG GTA CCT T-3', Cx3cr1 reverse: 5'-GCT GCA CTG TCC GGT TGT T-3', Il1r2 forward: 5'-GAA TAC ACA GCT CCA GGC TCC-3', Il2r1 reverse: 5'-TGA ACA TTG TCC GCA CCA AC-3', Trfforward: 5'-TGT GAC CTG TGT ATT GGC CC-3', Trf reverse: 5'-AAC GAG ACA CCT GAA AGC CC-3', Hprt1 forward: 5'-GAG GAG TCC TGT TGA TGT TGC CAG-3', Hprt1 reverse: 5'-GGC TGG CCT ATA GGC TCA TAG TGC-3'.

Gene enrichment analysis

Enrichment analysis was performed using the Database for Annotation, Visualization and Integrated Discovery (DAVID) version 6.7 [43, 44]. 46 genes which are differentially expressed when comparing SRL ${ }^{-/-}$ vs. $\mathrm{RL}^{-/-}$monocytes (up- or down-regulated) were used for the identification of enriched Gene Ontology (GO) terms and Kyoto Encyclopedia of Genes and Genomes (KEGG) pathways. This procedure used a modified Fisher's exact test (EASE score) with thresholds for minimum gene count $=2$ and EASE $p$-value $=0.05$ to find GO term and KEGG pathway annotations significantly enriched in the differentially expressed gene list. The Benjamini-Hochberg method is used for adjustment of multiple testing as implemented in DAVID. 


\section{Transcription factor network and WGCNA}

The expression data of transcription factors contained in the dataset were used for creating a transcription factor co-expression network using Biolayout Express3D version 3.3 [45]. Transcription factors derived from TFCat database (http://www.tfcat.ca) were set as nodes and connecting edges were determined by Pearson correlation coefficient of $>0.85$ [46]. The obtained network was visualized using Cytoscape version 3.4.0 [47]. The graph was colored according to the respective log2-transformed fold changes (FC) obtained from the $\mathrm{SRL}^{-/-}$vs. $\mathrm{RL}^{-/-}$differential gene expression analysis. The strength of coexpression was represented by edge thickness.

The TF network was complemented by a weighted gene co-expression network analysis (WGCNA) of the global gene expression dataset. Gene modules containing co-expressed genes have been identified using the WGCNA R-package [48]. For this, we created a scale-free signed co-expression network based on biweight mid-correlation coefficients (deepSplit parameter $=2$, detectCutHeight $=0.95$ ) and determined the eigengenes for each co-expression module. Identified modules are named by color code as suggested by the WGCNA package.

\section{Results}

Deletion of SOCS-1 results in a loss of bone marrow derived Ly6C low monocytes

In our previous study, we observed an increase of CD $11 \mathrm{~b}^{+}$monocytes in bone marrow as well as in the blood of SRL $\mathrm{L}^{-1-}$ mice that was mainly due to an increase in the Ly6 $\mathrm{C}^{\text {high }}$ monocyte subset [19]. To further elucidate the influence of SOCS-1 on monocyte subset distribution, we analyzed the different Ly6C subsets of monocytes isolated from bone marrow of SRL ${ }^{-1-}$, $\mathrm{RL}^{-/-}$and $\mathrm{L}^{-/-}$mice by FACS. The applied FACS gating strategy is visualized in Fig. $1 \mathrm{~A}$ and described in detail in Material and Methods (see 4.4). As previously reported, an overall increase of $\mathrm{CD}_{11} \mathrm{~b}^{+}$monocytes in the total amount of living cells from $12.1 \%\left(\mathrm{~L}^{-/-}\right)$and $14.3 \%\left(\mathrm{RL}^{-/-}\right)$to $20.4 \%$ in $\mathrm{SRL}^{-/-}$mice was observed (Fig. 1B). In $\mathrm{RL}^{-/-}$mice, the increase in monocytes is apparently an artifact of the mouse model used as these mice lack B cells which are normally strongly represented in the bone marrow. However, the amount of monocytes increases further due to the loss of SOCS-1. Exemplary density plots for the distribution of Ly6C monocytes and the corresponding bar graph illustrate that both genetic knockouts the loss of RAG2 as well as the loss of SOCS-1 - are responsible for distinct changes in the monocyte subsets. While the increase in Ly6 $\mathrm{C}^{\text {high }}$ monocytes is already caused by the loss of RAG2 (35.5\% in $\mathrm{L}^{-/-}$vs. $48.0 \%$ in $\mathrm{RL}^{-/-}$) and stays almost constant in comparison to $\mathrm{SRL}^{-}$ ${ }^{1-}$ mice $(46.6 \%)$, SOCS-1 deficiency reduces the amount of Ly6 $\mathrm{C}^{\text {low }}$ monocytes significantly from $11.7 \%\left(\mathrm{~L}^{-/-}\right)$and $9.6 \%\left(\mathrm{RL}^{-/-}\right)$to $3.4 \%\left(\mathrm{SRL}^{-/-}\right)$(Fig. $1 \mathrm{C}$ and $\left.1 \mathrm{D}\right)$.

\section{Quality control and determination of RNA integrity ensure optimal performance of $m R N A$} profiling

To decipher the genetic mechanisms how SOCS-1 influences gene expression in inflammatory and patrolling monocyte subsets, we performed an mRNA microarray expression analysis. Therefore, $\mathrm{Ly} 6 \mathrm{C}^{\text {high }}$ and $\mathrm{Ly} 6 \mathrm{C}^{\text {low }}$ monocytes isolated from bone marrow of $\mathrm{SRL}^{-1-}, \mathrm{RL}^{-1-}$ or $\mathrm{L}^{-/-}$mice were separated by cell sorting and total RNA from both subsets was isolated. As our study was critically dependent on the quality of the used samples, we first re-sorted the isolated monocyte subsets to verify the purity of the sorted cells (Fig. 2A). We could demonstrate that the purity of Ly $6 \mathrm{C}^{\text {high }}$ and Ly $6 \mathrm{C}^{\text {low }}$ monocyte subsets were $98.9 \%$ and $86.7 \%$ respectively. The lower purity in the Ly $6 \mathrm{C}^{\text {low }}$ monocyte subset was due to a lower cell concentration in the initial sample and a higher proportion of dead cells in comparison to the Ly6C $\mathrm{C}^{\text {high }}$ monocyte subset. Next, we validated RNA integrity for every sample that was subsequently used in the microarray. As the Ly $6 \mathrm{C}^{\text {low }}$ monocyte subset was the most critical group with regard to RNA yield, exemplary electropherograms and the corresponding RIN numbers of RNA that were isolated from the Ly6Clow monocyte subsets of $\mathrm{L}^{-1-}, \mathrm{RL}^{-1-}$ and $\mathrm{SRL}^{-/-}$mice were shown in Fig. 2B. To further elucidate if the sorted cells are indeed monocytes, we compared gene expression of markers specific B cells (CD79b), T cells (CD28) 
and NK cells (CD244) in Ly6C high monocyte subsets with the isolated PE-positive cell fraction which served as positive control (Fig. 2C).

Loss of SOCS-1 leads to an altered mRNA profile in monocyte subsets

The mRNA expression profile of the monocyte subsets was subsequently compiled using Illumina MouseWG-6 v2.0 Expression BeadChip microarrays $(45,200$ transcripts). To exclude any non-biological experimental variation of the microarray experiments, we performed a hierarchical clustering of all gene expression values (Fig. 3A). In fact, all samples clustered in terms of their group classification indicating that these samples have similar gene expression profiles and illustrating that no batch effects of the microarrays occurred. Next, we subjected the expression data of $\mathrm{SRL}^{-1-}, \mathrm{RL}^{-/-}$ and $\mathrm{L}^{-/-}$monocyte samples to a principal component analysis. We identified two general directions along which the implemented data had the largest spread (Fig. 3B). The first dimension of principal component 1 (PC1) had a proportion of variance of 0.16 and represented monocyte differentiation whereas the second dimension of principal component 2 (PC2) had a proportion of variance of 0.10 and represented the genetic background. To elucidate how SOCS-1 deficiency might influence the mRNA profile

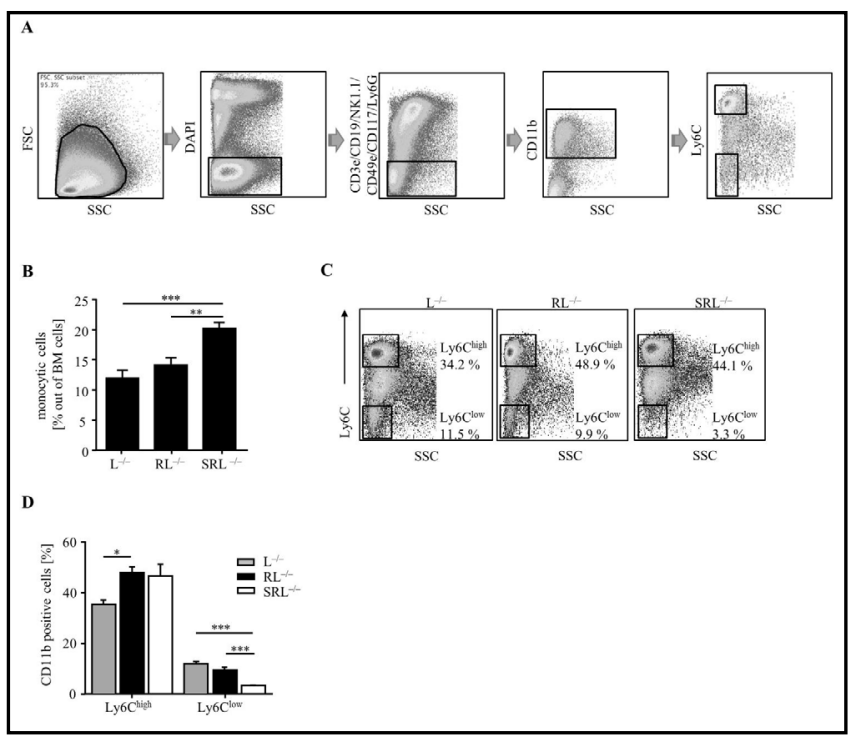

Fig. 1. Distribution of bone marrow-derived monocytes according to the expression of Ly6C by FACS analysis. (A) Representative FACS plots show the gating strategy used for the identification of murine monocyte subsets isolated from bone marrow based on their relative expression of Ly6C expression by all flow cytometry and cell sorting experiments. In brief, after exclusion of apoptotic cells by DAPI, a lineage negative selection was performed (CD3e, CD19, NK1.1, CD49b, CD117, Ly6G) to deplete mature hematopoietic cells and their committed precursors. The remaining cell fraction was gated for CD11b to include all monocytic cells and analyzed for the expression of Ly6C. (B) The increase in CD11 $\mathrm{b}^{+}$monocytes is illustrated for all three genotypes $\left(\mathrm{SRL}^{-/-}, \mathrm{RL}^{-/-}\right.$and $\mathrm{L}^{-/-}$) by plotting the percentage of CD11b positive cells within all living bone marrow cells. (C) Representative FACS dot blots of Ly6C expression on CD11 $\mathrm{b}^{+}$ monocytic cells derived from bone marrow of $\mathrm{SRL}^{-1-}, \mathrm{RL}^{-1-}$ and $\mathrm{L}^{-/-}$mice. The percentage of Ly6 $\mathrm{C}^{\text {high }}$ and Ly6 $\mathrm{C}^{\text {low }}$ monocyte subsets of each genotype within the depicted gates is given. (D) The distribution of $\mathrm{CD} 11 \mathrm{~b}^{+}$monocytes according to their expression of Ly6C illustrates the influence of RAG2 deficiency on Ly6 $\mathrm{C}^{\text {high }}$ monocyte subset as well as the influence of SOCS1 deficiency on Ly6C low monocyte subset. Data are shown as mean \pm SEM of 10 mice per group from three independent experiments. Significance was calculated in comparison to all other groups by one-way ANOVA/Tukey's test ${ }^{*} \mathrm{P}<0.05$, $\left.{ }^{* *} \mathrm{P}<0.01,{ }^{* * *} \mathrm{P}<0.001\right)$. of monocytes, we arranged the microarray data of both monocyte subsets (Ly6 $\mathrm{C}^{\text {high }}$ and Ly6 $\mathrm{C}^{\text {low }}$ ) from the differential expression analysis of SRL ${ }^{-1-} \mathrm{vs}^{-} \mathrm{RL}^{-}$ 1- mice in a volcano plot (Fig. 3C). The volcano plot gives an overview about all $p$-values and their corresponding FC for this differential expression analysis. All genes that were significantly differentially expressed between the two groups are highlighted in bold black. We identified 46 candidate genes of which 10 were up- and 36 were down-regulated upon SOCS-1 deficiency (Table 1). Of particular interest were genes involved in either monocyte differentiation (Cx3cr1, Csf1r) or inflammation (Il10ra, Fcgrt, Il1r2). The predicted gene 14085 (Gm14085) did not pass the applied fold change threshold of 2 but was further investigated 
because of its surprisingly low differential expression $\mathrm{p}$-value of $3.3^{*} 10^{-34}$. However, subsequent quantitative PCR analysis revealed no significant differential expression in the respective monocytes (data not shown). Therefore, the observed expression pattern of Gm14085 is likely due to signal artefacts and has been discarded.

In order to clarify if the deletion of Rag2 had any significant effect on the transcriptional level in monocytes, we performed an additional analysis for differentially expressed genes between $\mathrm{RL}^{-/-}$and $\mathrm{L}^{-/-}$as well as between $\mathrm{SRL}^{-}$ /- and $\mathrm{L}^{-/-}$monocytes (Fig. 3D, Supplemental Tables 1 and 2 - all supplementary material available at www. cellphysiolbiochem.com). The analysis revealed 26 genes that were differentially expressed between $\mathrm{RL}^{-/-}$and $\mathrm{L}^{-/-}$ monocytes. None of them was detected in comparison $\mathrm{SRL}^{-/-}$vs. $\mathrm{RL}^{-/-}$indicating that our results from analysis $\mathrm{SRL}^{-/-}$vs. $\mathrm{RL}^{-/-}$ are not confounded by Rag2-dependant genes. Furthermore, almost all genes differentially expressed between $\mathrm{SRL}^{-1-}$

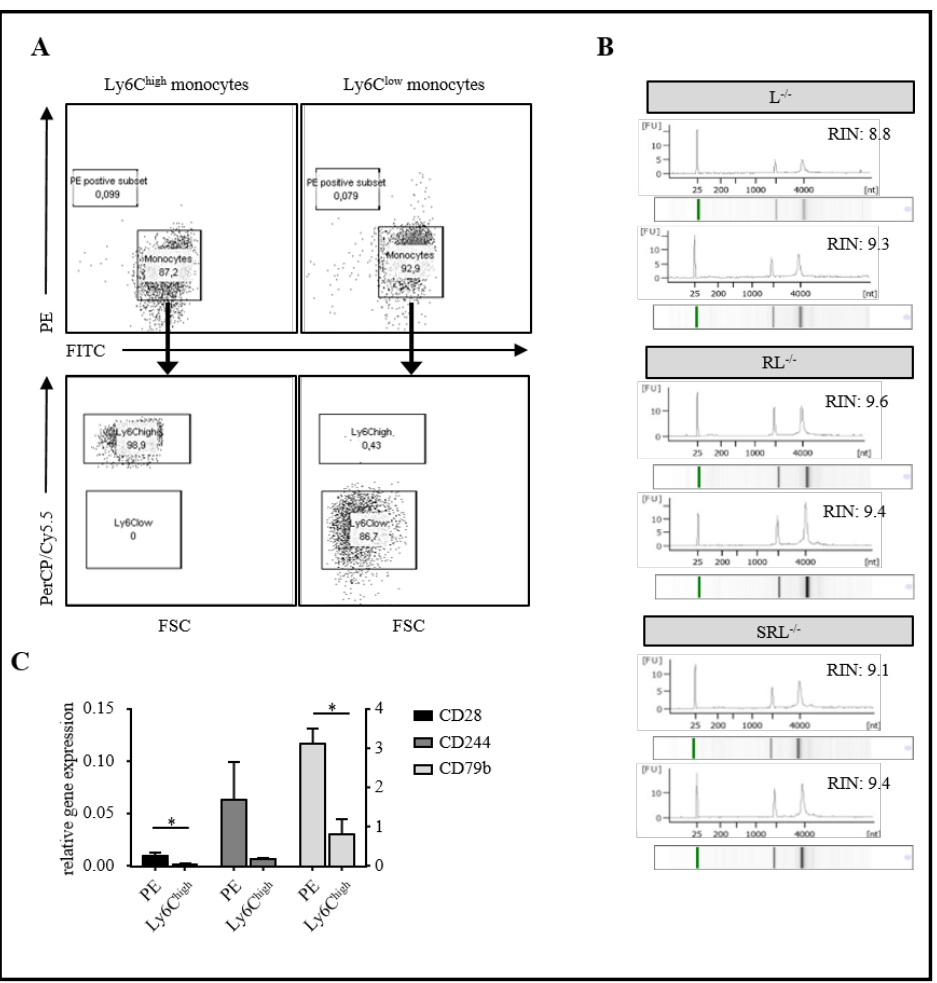

Fig. 2. Quality control of the sorted Ly6C $\mathrm{C}^{\text {high }}$ and Ly6 $6 \mathrm{C}^{\text {low }}$ monocyte subsets and the mRNA isolated from these cells. (A) Re-sort of Ly6Chigh and Ly $6 \mathrm{C}^{\text {low }}$ monocyte subsets by FACS exhibited a purity of $98.9 \%$ and $86.7 \%$ respectively. (B) Validation of RNA integrity that was isolated from Ly6Clow monocyte subsets from $\mathrm{L}^{-/-}, \mathrm{RL}^{-/-}$and $\mathrm{SRL}^{-/-}$mice was performed with an Agilent 2000 Bioanalyzer system. All RNA samples that were included in the microarray analysis were validated, but only two exemplary electropherograms and the corresponding RIN numbers of RNA are shown. (C) Validation of markers specific for B cells (CD79b), T cells (CD28) and NK cells (CD244) in Ly6 $\mathrm{C}^{\text {high }}$ monocyte subsets by real-time quantitative PCR (qPCR) in order to determine if the sorted cells originate from monocytes. The sorted PE-positive cell fraction served as positive control. Data are shown as mean \pm SEM of 3-4 mice per group from duplicates of two individual experiments. Significance was calculated by multiple t test and statistical significance was determined using the Holm-Sidak method with alpha $=5 \%$.

vs. $\mathrm{RL}^{-/-}$were also differentially expressed between $\mathrm{SRL}^{-/-}$vs. $\mathrm{L}^{-/-}$(42 of 46 genes; those 4 genes not differentially expressed in the latter group comparison are Hpgd, Igl-5, Tcea3 and Cc19) suggesting that SOCS-1 is potentially involved in the transcriptional regulation of the genes.

SOCS-1 regulates the expression of surface receptors and monocyte factors

In order to analyze the gene expression profile of monocyte subsets in more detail, we performed a hierarchical clustering of all genes that were differentially expressed in Ly6 $\mathrm{C}^{\text {high }}$ and Ly6C low monocytes in a SOCS-1-dependent manner (SRL ${ }^{-/-} \mathrm{vs} . \mathrm{RL}^{-/-}$). The 46 observed genes were depicted in a heatmap according to the hierarchical clustering of their expression profiles throughout the samples (Fig. 4A). For the majority of genes, the expression was downregulated by the loss of SOCS- 1 . As illustrated by the left-hand dendrogram, the expression profiles were divided into two main gene clusters. Of note, the expression of 


\section{A}

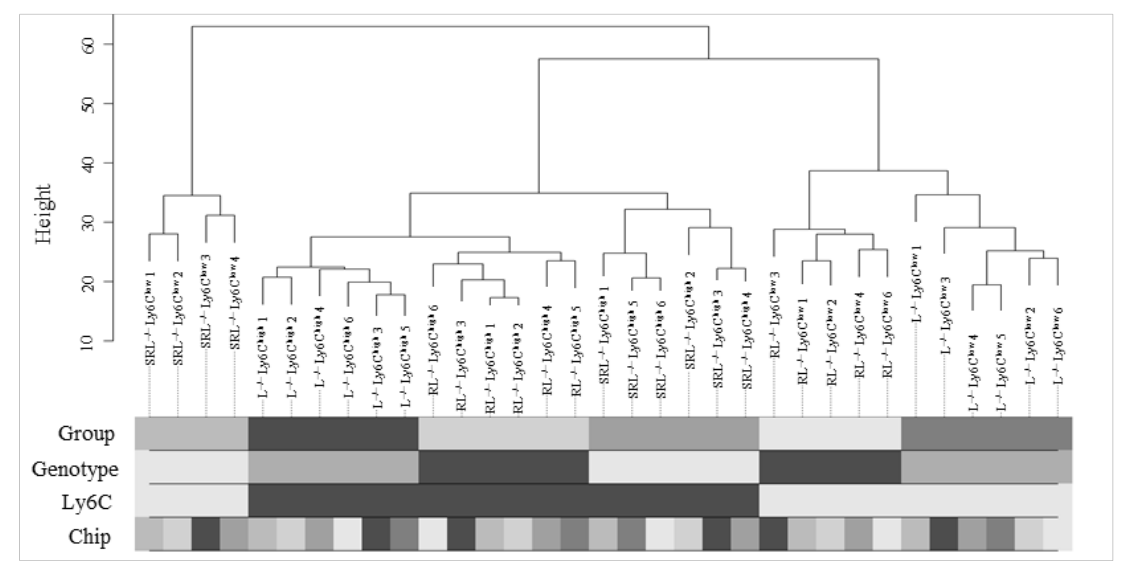

B

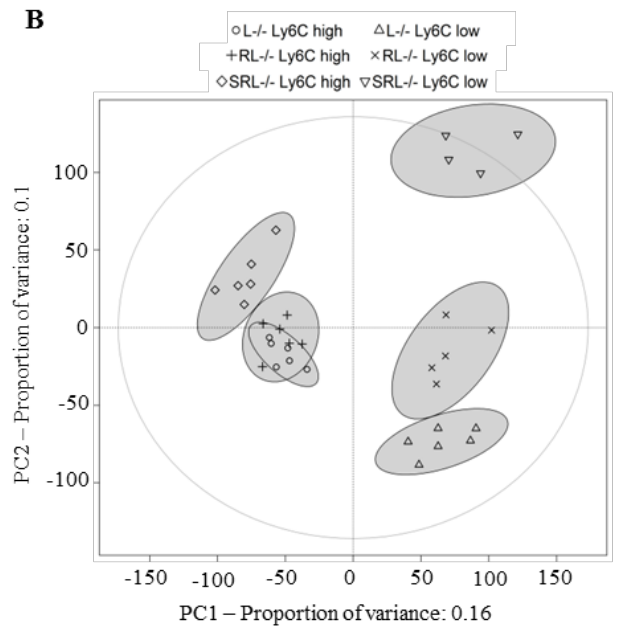

D

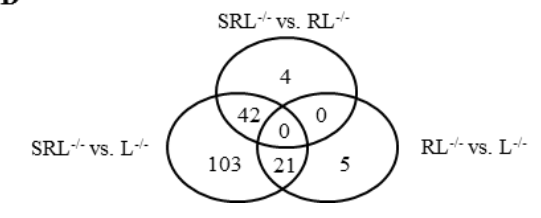

C

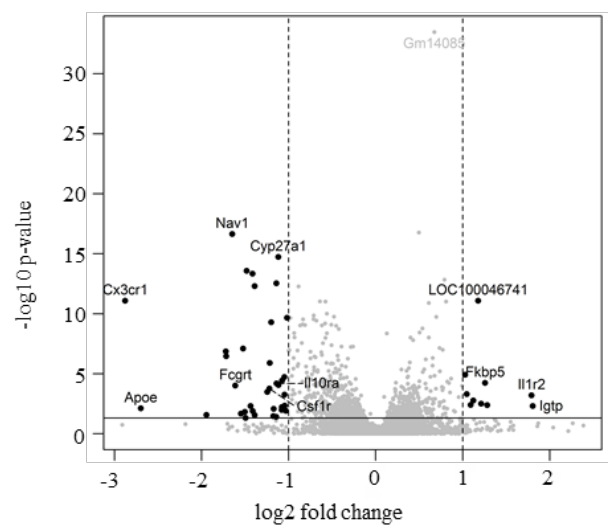

Fig. 3. Microarray analysis of mRNA expression from sorted bone marrow-derived monocyte subpopulations of $\mathrm{SRL}^{-/-}, \mathrm{RL}^{-/-}$and $\mathrm{L}^{-/-}$mice. (A) Hierarchical clustering of $\mathrm{SRL}^{-/-}, \mathrm{RL}^{-/-}$and $\mathrm{L}^{-/-}$samples are shown as sample dendrogram. Samples are annotated by grayscale codes indicating respective group replicates, genotype (SRL ${ }^{-/-}, \mathrm{RL}^{-/-}, \mathrm{L}^{-/-}$), Ly6C expression (high, low) and microarray allocation (6 arrays in total). (B) Principal component analysis (PCA) of mRNA expression data is illustrated using the first two principal components. The plot illustrates the projection of all $\mathrm{SRL}^{-/-}, \mathrm{RL}^{-/-}$and $\mathrm{L}^{-/-}$monocyte samples onto the first principal component (PC1) with a proportion of variance of $16 \%$ and the second principal component (PC2) with a proportion of variance of 10\%. Monocyte subsets from 4-6 mice were analyzed per group. (C) Volcano plot analysis from the analysis $\mathrm{SRL}^{-/-}$vs. $\mathrm{RL}^{-/-}$for the visual identification of genes with statistically significance and a large magnitude fold change. Vertical dashed lines indicate $\log 2$-transformed $+/-2.0$-fold changes and horizontal solid line denotes -log10-transformed p-values $<0.05$. Thick black dots represent differentially expressed mRNAs of $\mathrm{SRL}^{-/-}$and $\mathrm{RL}^{-/-}$monocytes. Data from 9-10 mice per group are shown. (D) Venn diagram illustrating the effects of the RAG2 deletion on the one hand and the SOCS-1 deletion on the other hand on the differential gene expression in $\mathrm{SRL}^{-/-}, \mathrm{RL}^{-/-}$and $\mathrm{L}^{-/-}$monocytes. 
Cellular Physiology Cell Physiol Biochem 2019;52:336-353

\begin{tabular}{ll|l} 
and Boll 10.33594/000000024 & O 2019 The Author(s). Published by \\
Cell Physiol Biochem Press GmbH\&Co. KG
\end{tabular}

Schuett et al.: SOCS-1-Dependent Gene Regulation

Table 1. Identification of 46 genes differentially expressed in Ly6 $\mathrm{C}^{\text {high }}$ and Ly6 $6 \mathrm{C}^{\text {low }}$ monocytes upon SOCS-1 deficiency (SRL ${ }^{-/-}$vs. $\mathrm{RL}^{-/-}$)

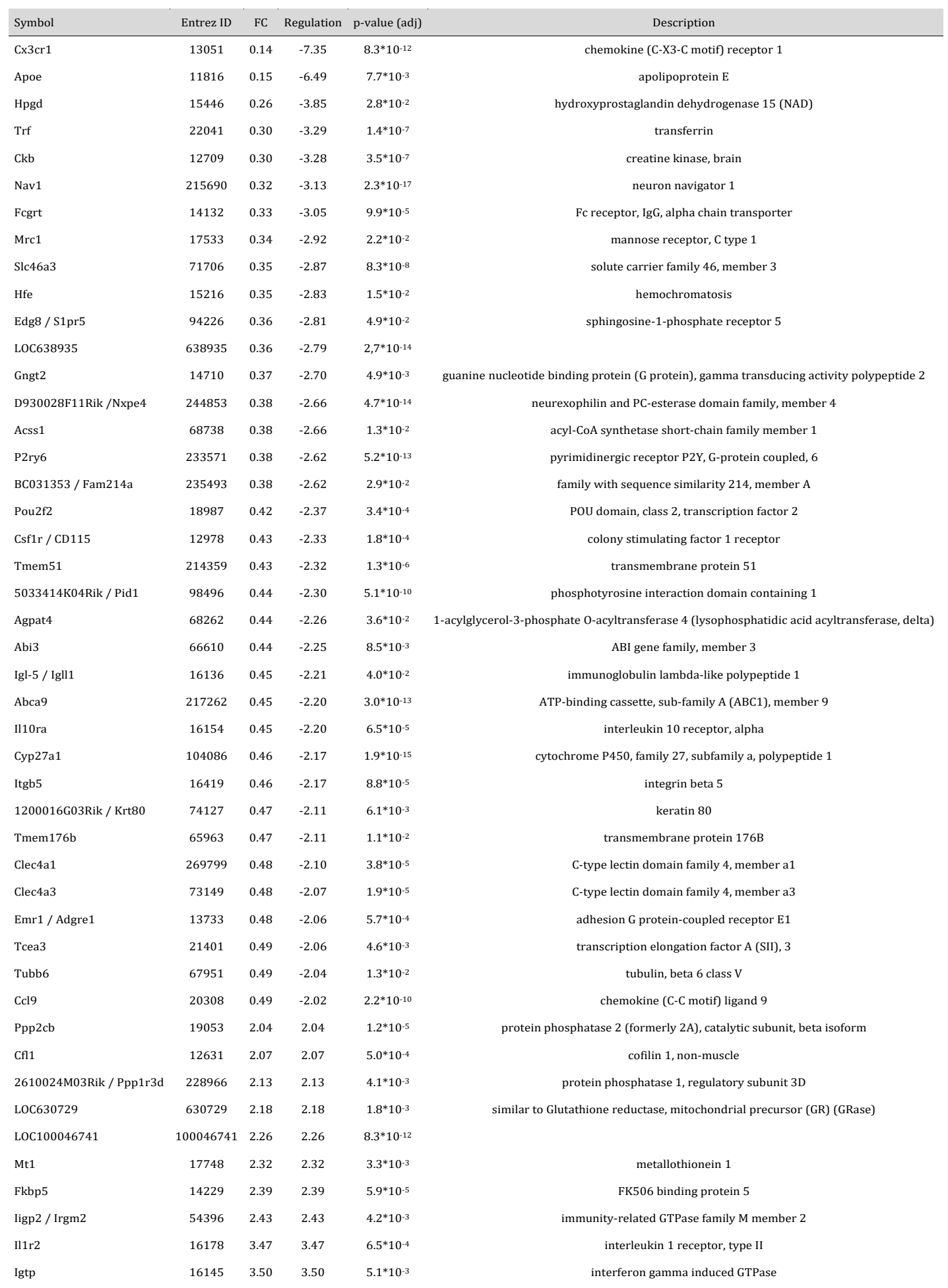


several genes of the upper expression cluster encoding for surface markers which delineate monocyte subsets (Csf1r, Cx3cr1, Emr1) was diminished indicating a critical role of SOCS-1 in monocyte differentiation. Especially $C \times 3 c r 1$ and $E m r 1$, which encodes for the cell surface glycoprotein F4/80, show close co-expression according to the gene clustering. The results of the microarray data regarding the differential expression patterns were confirmed by real-time quantitative PCR for selected genes (Fig. 4B).

In order to identify over-represented classes of gene functions of the 46 differentially expressed genes between SRL ${ }^{-/-}$vs. $\mathrm{RL}^{-/-}$mice, a gene enrichment analysis was performed for GO terms and KEGG pathways. Supplemental Table 3 displays the pathways and GO terms that were detected, the corresponding genes and enrichment p-values. Besides GO terms for cellular components like membrane and cell surface, we identified terms for molecular functions like GTPase activity (IIgp2, Gngt2, Igtp, Tubb6) and signal transducer activity (Emr1, Edg8, Cx3cr1, Gngt2, P2ry6) as well as the KEGG pathway for cytokine-cytokine receptor interaction (Il1r2, Cx3cr1, Csf1r, Il10ra). However, none of these terms shows significant enrichment after adjustment for multiple testing. Therefore, these results need to be viewed with caution.

Transcription factor network analysis reveals alterations in PPAR- $\gamma$, NUR77 and the ETSdomain family

To further analyze the transcription factors (TF) that might be responsible for the altered gene expression profile in $\mathrm{SRL}^{-/-}$mice, we created a correlation matrix of all transcription factors throughout all samples of our dataset. The generated network included all TF that were correlated with at least one other TF with $r>0.85$ (Fig. 5). This network was combined with data from gene co-expression modules obtained from a weighted gene co-expression network analysis (WGCNA) using the global gene expression data set (indicated by node border color in Fig. 5). The WGCNA identified in total 16 different co-expression modules, which are designated by color code. Of these, mainly three modules (yellow, black and blue module) are part of the presented TF network. Interestingly, the expression profiles of these three modules appear to differ mainly with respect to the $\mathrm{SRL}^{-1-}$ Ly6Clow monocytes, as indicated by the module eigengene boxplots in Fig. 6 . The grey module is the default module for all genes not assigned to any module. For reasons of clarity, the presented network includes TFs only, while all members of a module have been used for gene enrichment analysis.

The only TF in the network which has been detected as significantly differentially expressed between $\mathrm{SRL}^{-/-}$and $\mathrm{RL}^{-/-}$mice according to the applied fold change and $\mathrm{p}$-value threshold is Pou2f2 (POU domain, class 2, transcription factor 2), which is known in humans to bind to a common TF binding site in immunoglobulin gene promoters. This down-regulated TF is strongly co-expressed with Pparg (peroxisome proliferator activated receptor gamma), which has - besides its implication in fatty acid and energy metabolism - a strong impact on the reduction of inflammation and the balance of immune cells. Furthermore, it is beneficial for endothelial function. Interestingly, Pparg is not differentially expressed when comparing all $\mathrm{SRL}^{-/-}$vs. $\mathrm{RL}^{-/-}$monocytes, but is strongly differentially expressed for the same mice when comparing the Ly6C low monocytes only (FC: 0.23 , p-value: $2.86^{*} 10^{-11}$ ). We validated this observation by qPCR for the comparison of Ly6C ${ }^{\text {low }}$ monocytes from $\mathrm{RL}^{-/-}$and SRL ${ }^{-/-}$mice (FC: 0.036 , p-value: $5.17^{*} 10^{-9}$ ). We observed Pparg to be significantly differentially expressed between Ly6 $\mathrm{C}^{\text {high }}$ and Ly6 $6 \mathrm{C}^{\text {low }}$ monocytes for $\mathrm{RL}^{-/-}$mice (FC: 0.23 , p-value: $3.78^{*} 10^{-12}$ ) as well as for $\mathrm{L}^{-/-}$mice (FC: 0.16 , p-value: $4.22^{*} 10^{-13}$ ), but this effect is mostly gone for the $\mathrm{SRL}^{-/-}$mice (FC: 0.81 , p-value: 0.017 ), indicating SOCS-1 as a regulator of Pparg during monocyte subtype differentiation. PPAR- $\gamma$ is part of a highly interconnected sub-network comprising TFs that play an important role in gene transcription during immune response. Amongst them are members of the nuclear factor of activated T-cells (NFATC1, NFATC3), nuclear factor kappa b subunit 2 (NFKB2) as well as the orphan nuclear receptor NR4A1 (also known as NUR77), which functions as a master regulator of differentiation and survival of Ly6C $\mathrm{C}^{\text {low }}$ monocytes. According to the WGCNA analysis of global gene expression, these transcription factors are 


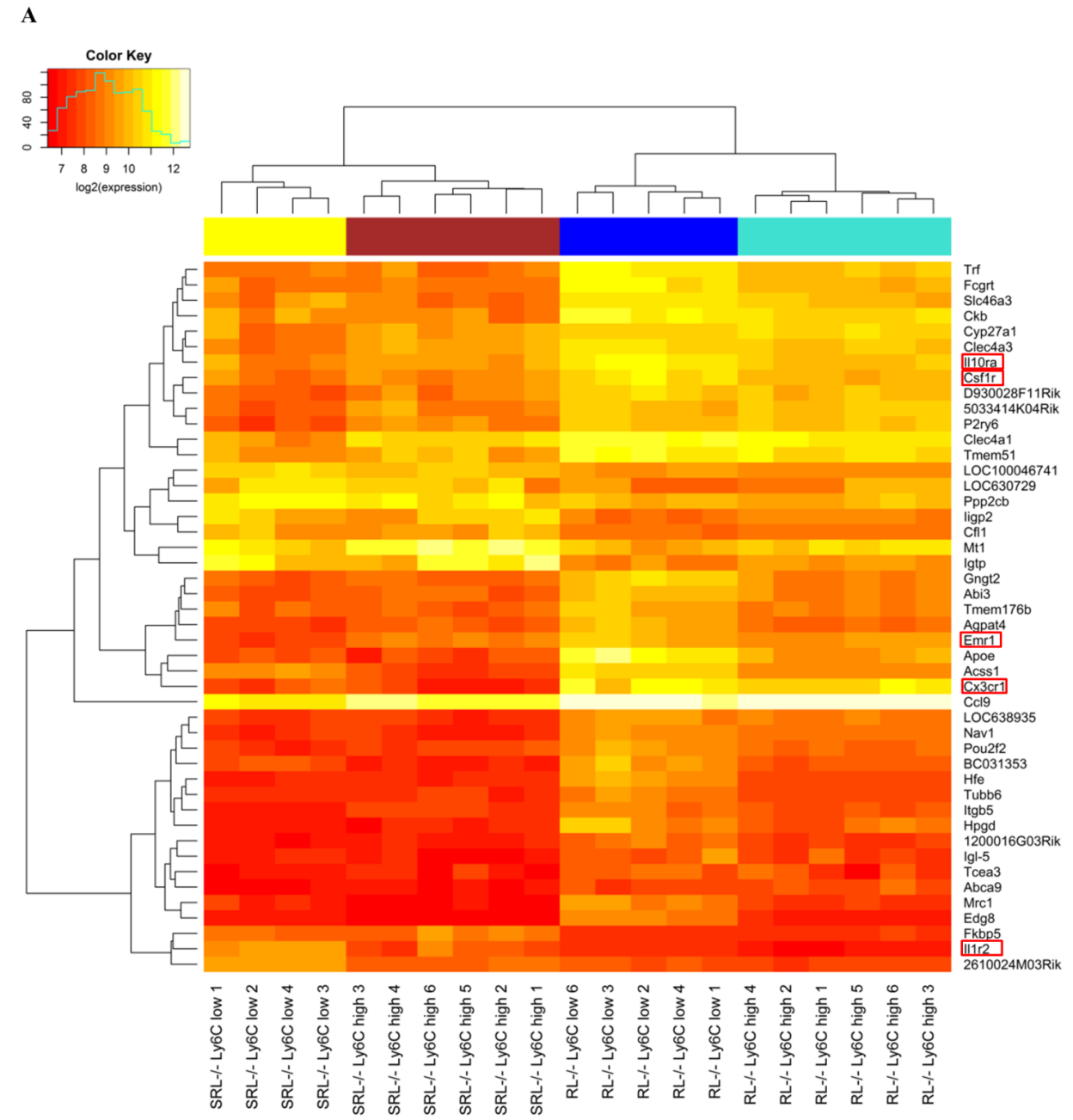

B
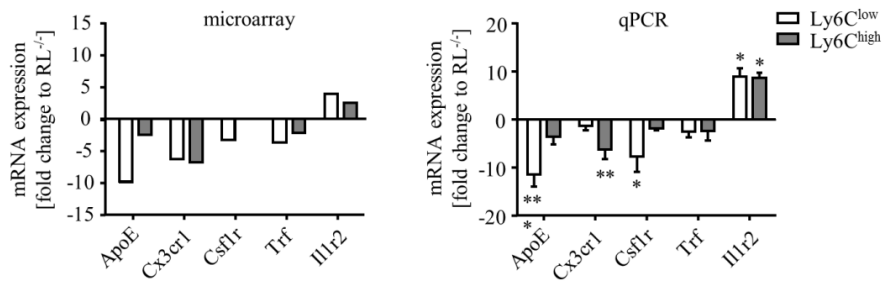

Fig. 4. Visualization of differential expression mRNA patterns of $S R L^{-1-}$ and $\mathrm{RL}^{-/-}$monocytes. The mRNA microarray data was analyzed for different expression patterns of SRL ${ }^{-/-}$and $\mathrm{RL}^{-/-}$monocyte subsets. (A) Heat map represents 46 genes that are differentially regulated in a SOCS-1 dependent manner (SRL ${ }^{-/-} \mathrm{vS}^{-1}$ $\mathrm{RL}^{-/}$). Genes with a corrected differential expression $\mathrm{p}$-value $<0.05$ and fold change $>2$ or less than 0.5 were considered significantly regulated. The color key and histogram indicate the degree and distribution of log2-transformed expression intensities. Color bars on top of the heatmap indicate genotype and monocyte subset. Yellow: SRL ${ }^{-/-}$Ly6C low. Brown: SRL ${ }^{-/-}$Ly6C high . Blue: $\mathrm{RL}^{-/-}$Ly6Clow. Turquoise: $\mathrm{RL}^{-/-}$Ly6C $\mathrm{C}^{\text {high }}$. n=4-6 per group. (B) mRNA expression of selected genes from SRL $\mathrm{SR}^{-/}$and $\mathrm{RL}^{-/-}$monocyte subsets was validated by qPCR. To determine the dependency on SOCS-1, the FC of mRNA expression from SRL ${ }^{-/-}$monocytes to the reference $\left(\mathrm{RL}^{-/-}\right)$is shown and compared to the expression patterns of the microarray. Hprt1 was used as housekeeping gene for qPCR. Data are shown as mean \pm SEM of 4-7 mice per group from duplicates of three independent experiments. Significance was calculated in comparison to $\mathrm{RL}^{-/-}$by one-way ANOVA/Dunnett's test $\left({ }^{*} \mathrm{P}<0.05, * * \mathrm{P}<0.01,{ }^{* * *} \mathrm{P}<0.001\right)$. 


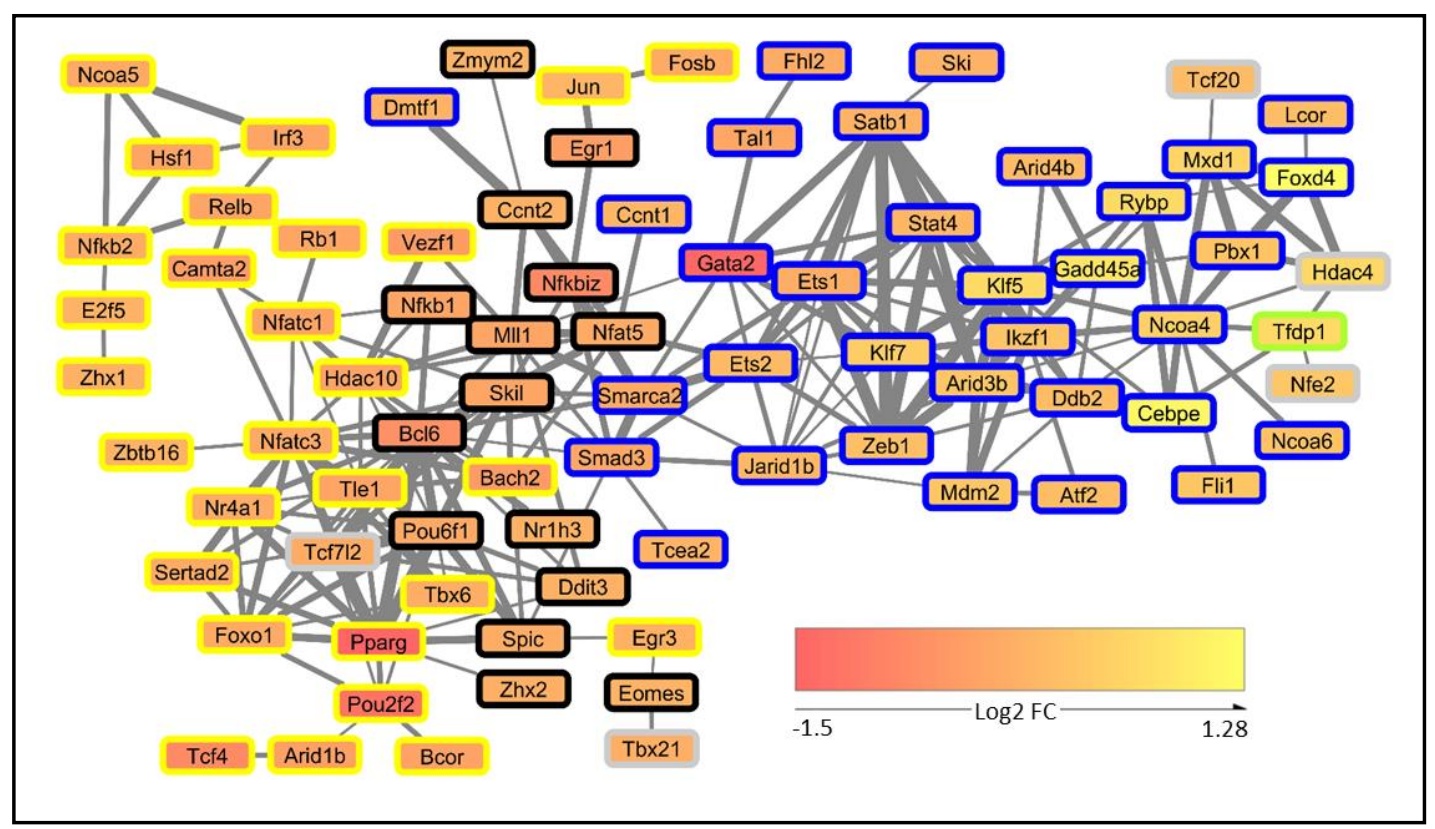

Fig. 5. Network of transcription factors from SOCS-1 dependent mRNA expression data. The expression data of transcription factors contained in the dataset were used for creating a transcription factor coexpression network using Biolayout Express3D. The network comprises all transcription factors (TFs) that correlate at least with one other TF with $r>0.85$. The obtained network was visualized using Cytoscape. The edge thickness represents the correlation ranging from 0.85 to 0.97 and the node colors represent the $\log 2$-transformed FC detected in the $\mathrm{SRL}^{-/-}$vs $\mathrm{RL}^{-/-}$differential expression analysis (red: down-regulated, yellow: up-regulated). The TFs were further annotated with gene co-expression modules obtained from a weighted gene co-expression network analysis (WGCNA) using the global gene expression data set. Module membership is indicated by node border color.

part of a 2111 genes comprising co-expression module (yellow module in Fig. 6), which also includes the cell-surface receptors CX3CR1 and CSF1R. Enrichment analysis of the genes of this module revealed the KEGG pathways osteoclast differentiation and MAPK signaling pathway to be significantly enriched (Supplemental Table 4).

Further co-expressed TFs regulate differentiation of tissue-resident macrophages such as Kupffer cells (NR1H3) and red pulp macrophages (SPI-C) which belong to the black expression module containing 534 genes. In the black module, which interacts with the yellow as well as with the blue gene expression module, NF-kappa B signaling pathway as well as $\mathrm{T}$ cell receptor signaling pathway and B cell receptor signaling pathway are significantly enriched (Supplemental Table 5).

Of note, several TFs in the network belong to the ETS-domain family (ETS1, ETS2, FLI-1). These TFs usually interact with different co-regulatory factors to induce or repress distinct biological processes. They are known to regulate cell proliferation, apoptosis and senescence, but they also promote differentiation of hematopoietic cells. These TFs belong to the blue co-expression module (2386 genes), which is enriched for the GO term immune system process as well as for the KEGG pathways leukocyte transendothelial migration and MAPK signaling pathway (Supplemental Table 6). Interestingly, genes that we identified by differential gene expression analysis and which play a major role in monocytic cell differentiation (Csf1r, Emr1) reveal potential binding sites for ETS-domain family members in their promotor regions thus making these transcription factors feasible targets for the SOCS-1-dependent loss of Ly6C $\mathrm{C}^{\text {low }}$ monocytes. 


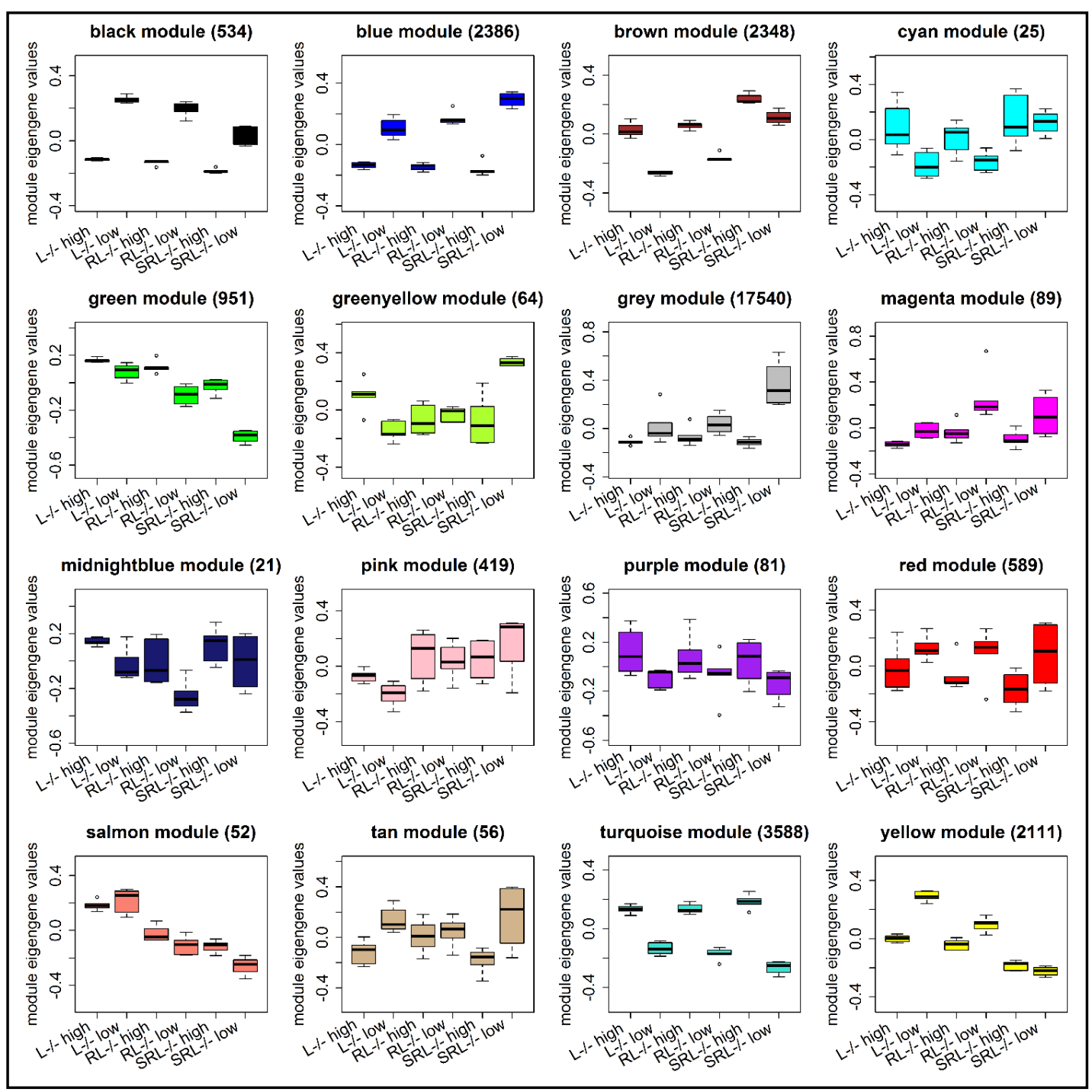

Fig. 6. Boxplots of module eigengenes for all gene co-expression modules identified by WGCNA. The co-expression modules were identified for the global expression dataset and are plotted group-wise in boxplots. The numbers given in brackets behind the module names indicate the number of genes belonging to a certain module. The color code of the module names is used as a node border color in Fig. 5 to indicate module membership of depicted transcription factors.

\section{Discussion}

As we have described previously, loss of SOCS-1 leads to an accumulation of monocytes in bone marrow, blood and spleen of atherosclerotic-prone mice (SRL ${ }^{-/-}$) thereby aggravating atherosclerotic plaque burden [19]. But contrary to our previous observations in which we traced this increase back to an accumulation of Ly6 $\mathrm{C}^{\text {high }}$ monocytes, we could now demonstrate by considering the relative changes in Ly6 $\mathrm{C}^{\text {high }}$ and Ly6C $\mathrm{C}^{\text {low }}$ monocyte subsets that the increase in Ly6 $\mathrm{C}^{\text {high }}$ monocytes already occurs due to the loss of RAG2 even without any disturbance in SOCS-1 (RL-/-). The additional deficiency in SOCS-1 rather causes a significant reduction in the Ly $6 \mathrm{C}^{\text {low }}$ monocytic cell population indicating that SOCS-1 has a strong impact on the conversion of Ly6 $\mathrm{C}^{\text {high }}$ into more mature Ly6 $\mathrm{C}^{\text {low }}$ monocytes. 
Indeed, Ly6C $\mathrm{C}^{\text {low }}$ monocytes from $\mathrm{SRL}^{-/-}$mice display a specific mRNA signature that strongly differs from all other identified clusters. The detailed analyses of differentially expressed genes revealed that SOCS-1 deficiency leads to an alteration in mRNA expression that affects cell surface markers which are crucial for the homeostatic control of Ly6Clow monocytes. One of these genes encodes for the chemokine receptor CX3CR1 which is normally strongly expressed on monocytes and which is getting downregulated during differentiation into macrophages [20]. In bone marrow-derived monocytes from SRL ${ }^{-/-}$mice and in inflammatory Ly6 $\mathrm{C}^{\text {high }}$ monocytes in particular, $\mathrm{Cx} 3 \mathrm{cr} 1$ expression is significantly diminished. It is known from the literature that the deletion of $C \times 3 \operatorname{cr} 1$ results in reduced numbers of patrolling Ly6C $\mathrm{C}^{\text {low }}$ monocytes [7]. Additionally, Cx3cr1 deficiency is as well associated with an augmented infiltration of inflammatory Ly6 $\mathrm{C}^{\text {high }}$ monocytes [21]. With regard to atherosclerosis, it has been shown that pharmacological inhibition of CX3CR1 reduces the extent of atherosclerotic lesions in both $\mathrm{ApoE}^{-/-}$and $\mathrm{Ldlr}^{-/-}$mice [22]. This is not in line with our previous study in which we observed an enhanced atherosclerotic plaque burden in $\mathrm{SRL}^{-/-}$mice. An explanation for this discrepancy could be that pharmacological inhibition of CX3CR1 targets circulating monocytes while SOCS-1 deficiency results in a reduced $C x 3 \operatorname{cr} 1$ expression in monocytes from bone marrow.

Besides the diminished expression of lineage specific markers like Cx3cr1 or Emr1, loss of SOCS-1 also caused a reduced receptor expression that are pivotal for cytokine signal transduction. In this context it is hardly surprising that SOCS-1 deficiency alters regulation of cytokine receptors that signal either via the JAK/STAT pathway (IL10RA) or MYD88 (IL1R) [13]. Interestingly, the latter seems to be inhibited upon SOCS-1 deficiency by the upregulation of the IL1 receptor mimetic IL1R2 that is able to block IL1 signaling completely [23]. Why IL1R2 is strongly upregulated in both monocyte subsets of SRL ${ }^{-/}$mice still remains to be elucidated. Of note, CSF1R (also known as CD115) is another important receptor which is only expressed on cells of the mononuclear phagocytic lineage and which is significantly downregulated due to loss of SOCS-1. Colony stimulating factor 1 (CSF1) is the most important growth factor that regulates differentiation and maturation of macrophages from monocytes, but also survival of these cells [24]. Mice with a natural mutation in the CSF1 gene are severely depleted of macrophages in most tissues, accompanied by severe growth retardation, osteopetrosis and other developmental abnormalities [25]. A null mutation of Csf1r manifests in even more severe phenotypes, including postnatal mortality [26]. It has already been shown that SOCS-1 serves as a CSF1R binding partner that negatively regulates proliferation and affects cytokine receptor signaling [27]. Similar to the deletion of SOCS1 , blocking CSF1R by antibody treatment leads to a reduction in Ly6C low monocytes that is accompanied by an increase in Ly6C $\mathrm{C}^{\text {high }}$ monocytes further underlining the involvement of SOCS-1 in CSF1R-dependent monocyte maturation [28]. In a mouse model of myocardial infarction, the inhibition of CSF1R signaling also results in a decline of Ly6C low monocytes in the circulation and a subsequent depletion of M2 macrophages in the heart that is associated with a reduced heart function [29]. With regard to atherosclerosis, it has been shown in several different studies that pharmacological inhibition of CSF1 as well as a Csf1 null mutation in mice with either $A p o E^{-/-}$or $\mathrm{Ldlr}^{-/}$background reduces atherogenesis [30-32]. In contrast, a recent study in hyperlipidemic rabbits reveals that administration of human CSF1 suppresses atherosclerotic lesions, inter alia through the stimulation of ApoE secretion [33]. This observation is in parallel with our data that shows less gene induction of $A p o E$ in monocyte subsets of SRL ${ }^{-/-}$mice potentially as a result of a diminished expression of Csf1r.

The TF network analysis revealed possible underlying mechanisms of transcriptional regulation due to SOCS-1 deficiency that involve the transcription factors PPAR- $\gamma$, NR4A1 as well as different members of the ETS-domain family. PPAR- $\gamma$ is well known as pivotal transcription factor for differentiation of monocytes into alveolar macrophages [34]. In human atherosclerotic lesions, monocytes can be activated by PPAR- $\gamma$ to differentiate into alternative M2 macrophages with anti-inflammatory properties [35]. Here we find PPAR- $\gamma$ to be significantly down-regulated upon SOCS-1 depletion during monocyte subtype differentiation, since the Pparg expression observed in $\mathrm{RL}^{-/-}$Ly6Clow monocytes and $\mathrm{L}^{-/-}$ 


\section{Cellular Physiology Cell Physiol Biochem 2019;52:336-353 \\ \begin{tabular}{ll|l} 
and Biochemistry & $\begin{array}{l}\text { DOl: 10.33594/000000024 } \\
\text { Published online: } 28 \text { February } 2019\end{array}$ & $\begin{array}{l}\text { O } 2019 \text { The Author(s). Published by } \\
\text { Cell Physiol Biochem Press GmbH\&Co. KG }\end{array}$ \\
\cline { 2 - 3 } & Scher
\end{tabular} \\ Schuett et al.: SOCS-1-Dependent Gene Regulation}

Ly6 $\mathrm{C}^{\text {low }}$ monocytes is inhibited in $\mathrm{SRL}^{-/-}$Ly6 $\mathrm{C}^{\text {low }}$ monocytes. Pparg is highly co-expressed with $N r 4 a 1$, which both belong to the yellow sub-cluster of co-expressed genes which is enriched for genes involved in osteoclast differentiation. While the pivotal role of $\mathrm{Nr} 4 a 1$ in the differentiation and function of Ly6 $\mathrm{C}^{\text {low }}$ monocytes has already been acknowledged for several years, its impact in regulating the migration and recruitment of osteoclast precursors during bone remodeling was only recently reported [36]. Besides the highly coexpression of Pparg and Nr4a1, other TFs like Nfatc1, Jun and Fos are co-expressed in the yellow sub-cluster which are also indispensable for osteoclast differentiation. Together with the observed phenotype of the SRL mice that exhibit a significant growth retardation and show indications of osteopenia, these results strongly suggest that SOCS-1 is not only playing a central role in monocyte differentiation but also in osteoclast development.

The yellow sub-cluster interacts with the black and the blue sub-cluster, which contains members of the Ets-domain family. It is known that ETS-domain proteins interact with a multitude of different co-regulatory factors to regulate a complex network of biological processes [37]. In acute myeloid leukemia cells, one of these interactions is described for NR4A1 which binds to distal enhancers that are co-enriched for NR4A1 and ETS transcription factor motifs. This binding leads to a recruitment of ETS-domain proteins ERG and FLI-1 which in turn promote histone acetylation (H3K27). Besides this transcriptional activation, NR4A1 can also directly repress genes like the important myeloid transcription factor PU.1 which is known to control the expression of $C s f 1 r$ of the yellow co-expression module and to regulate CSF1R dependent cell survival [38]. Although PU.1 cannot directly be found in the TF network, the ETS-domain transcription factor SPI-C is part of the identified black TF cluster. SPI-C is closely related to PU.1 and has the ability to recognize the same DNA consensus sequence, but has opposing effects to PU.1 on gene expression [39]. Furthermore, it has been shown that SPI-C is interacting with STAT6 thus regulating IL-4 induced gene expression [40]. IL-4 (blue module) in turn is known to induce the expression of SOCS-1 in macrophages which inhibits the expression of STAT6-responsive genes in a negative feedback loop [41].

\section{Conclusion}

In summary, our study gives new insights in the regulatory potential of SOCS-1 in relation to monocyte and osteoclast differentiation. We could demonstrate that SOCS-1 is causally involved in the maintenance of patrolling Ly $6 \mathrm{C}^{\text {low }}$ monocytes in the bone marrow of atherosclerosis-prone mice. Furthermore, our study revealed that SOCS-1 is implicated in a fine-tuned TF network regulating the expression of ETS-domain family members and central transcription factors like PPAR- $\gamma$ and NUR77, thereby influencing the expression of cell-surface receptors like CX3CR1 and CSF1R that are pivotal for myeloid differentiation. Future in vitro and in vivo analyses will help to further clarify the role of SOCS-1 in the fate of monocytes upon chronic inflammatory diseases.

\section{Abbreviations}

ApoE (apolipoprotein E); CSF1R (colony stimulating factor 1 receptor); CX3CR1 (C-X3-C motif chemokine receptor 1); DAPI (4',6-diamidino-2-phenylindole); FACS (fluorescenceactivated cell sorting); Hprt1 (hypoxanthine phosphoribosyltransferase 1); IL (interleukin); IFN (interferon); JAK (Janus kinase); LDLR (low density lipoprotein receptor); NR4A1 (nuclear receptor subfamily 4 group A member 1); RAG2 (recombination activating gene 2); SOCS (suppressor of cytokine signaling); STAT (signal transducers and activators of transcription); TF (transcription factor); TRF (transferrin). 


\section{Cellular Physiology Cell Physiol Biochem 2019;52:336-353 \\ \begin{tabular}{ll|l} 
and Biochemistry & $\begin{array}{l}\text { DOl: 10.33594/000000024 } \\
\text { Published online: } 28 \text { February } 2019\end{array}$ & $\begin{array}{l}\text { O } 2019 \text { The Author(s). Published by } \\
\text { Cell Physiol Biochem Press GmbH\&Co. KG }\end{array}$ \\
\cline { 2 - 3 } & Scher
\end{tabular} \\ Schuett et al.: SOCS-1-Dependent Gene Regulation}

\section{Acknowledgements}

We thank Daniela Beppler for her excellent technical assistance. This study was funded by the German Cardiac Society (DGK-0914-SOCS).

\section{Disclosure Statement}

The authors declare that the research was conducted in the absence of any commercial or financial relationships that could be construed as a potential conflict of interest.

\section{References}

1 Writing Group M, Mozaffarian D, Benjamin EJ, Go AS, Arnett DK, Blaha MJ, Cushman M, Das SR, de Ferranti S, Despres JP, Fullerton HJ, Howard VJ, Huffman MD, Isasi CR, Jimenez MC, Judd SE, Kissela BM, Lichtman JH, Lisabeth LD, Liu S, et al.: Heart Disease and Stroke Statistics-2016 Update: A Report From the American Heart Association. Circulation 2016;133:e38-360.

2 Hansson GK, Libby P: The immune response in atherosclerosis: a double-edged sword. Nat Rev Immunol 2006;6:508-519.

3 Libby P, Ridker PM, Hansson GK: Progress and challenges in translating the biology of atherosclerosis. Nature 2011;473:317-325.

4 Geissmann F, Manz MG, Jung S, Sieweke MH, Merad M, Ley K: Development of monocytes, macrophages, and dendritic cells. Science 2010;327:656-661.

5 Epelman S, Lavine KJ, Randolph GJ: Origin and functions of tissue macrophages. Immunity 2014;41:21-35.

- 6 Carlin LM, Stamatiades EG, Auffray C, Hanna RN, Glover L, Vizcay-Barrena G, Hedrick CC, Cook HT, Diebold S, Geissmann F: Nr4a1-dependent Ly6C(low) monocytes monitor endothelial cells and orchestrate their disposal. Cell 2013;153:362-375.

7 Auffray C, Fogg D, Garfa M, Elain G, Join-Lambert O, Kayal S, Sarnacki S, Cumano A, Lauvau G, Geissmann F: Monitoring of blood vessels and tissues by a population of monocytes with patrolling behavior. Science 2007;317:666-670.

8 Kurotaki D, Osato N, Nishiyama A, Yamamoto M, Ban T, Sato H, Nakabayashi J, Umehara M, Miyake N, Matsumoto N, Nakazawa M, Ozato K, Tamura T: Essential role of the IRF8-KLF4 transcription factor cascade in murine monocyte differentiation. Blood 2013;121:1839-1849.

9 Hanna RN, Carlin LM, Hubbeling HG, Nackiewicz D, Green AM, Punt JA, Geissmann F, Hedrick CC: The transcription factor NR4A1 (Nur77) controls bone marrow differentiation and the survival of Ly6Cmonocytes. Nat Immunol 2011;12:778-785.

10 Tacke F, Randolph GJ: Migratory fate and differentiation of blood monocyte subsets. Immunobiology 2006;211:609-618.

11 Qu C, Edwards EW, Tacke F, Angeli V, Llodra J, Sanchez-Schmitz G, Garin A, Haque NS, Peters W, van Rooijen N, Sanchez-Torres C, Bromberg J, Charo IF, Jung S, Lira SA, Randolph GJ: Role of CCR8 and other chemokine pathways in the migration of monocyte-derived dendritic cells to lymph nodes. J Exp Med 2004;200:12311241.

- 12 Starr R, Willson TA, Viney EM, Murray LJL, Rayner JR, Jenkins BJ, Gonda TJ, Alexander WS, Metcalf D, Nicola NA, Hilton DJ: A family of cytokine-inducible inhibitors of signalling. Nature 1997;387:917-921.

- 13 Yoshimura A, Naka T, Kubo M: SOCS proteins, cytokine signalling and immune regulation. Nat Rev Immunol 2007; 7:454-465.

14 Alexander WS, Starr R, Fenner JE, Scott GL, Handman E, Sprigg NS, Corbin JE, Cornish AL, Darwiche R, Owczarek CM, Kay TWH, Nicola NA, Hertzog PJ, Metcalf D, Hilton DJ: SOCS1 is a critical inhibitor of interferon gamma signaling and prevents the potentially fatal neonatal actions of this cytokine. Cell 1999;98:597-608.

15 Marine JC, Topham DJ, McKay C, Wang D, Parganas E, Stravopodis D, Yoshimura A, Ihle JN: SOCS1 deficiency causes a lymphocyte-dependent perinatal lethality. Cell 1999;98:609-616. 


\section{Cellular Physiology Cell Physiol Biochem 2019;52:336-353 \begin{tabular}{ll|l} 
and Biochemistry & $\begin{array}{l}\text { DOl: 10.33594/000000024 } \\
\text { Published online: } 28 \text { February } 2019\end{array}$ & $\begin{array}{l}\text { C 2019 The Author(s). Published by } \\
\text { Cell Physiol Biochem Press GmbH\&Co. KG }\end{array}$ \\
\cline { 2 - 3 } &
\end{tabular} \\ Schuett et al.: SOCS-1-Dependent Gene Regulation}

16 Ortiz-Munoz G, Martin-Ventura JL, Hernandez-Vargas P, Mallavia B, Lopez-Parra V, Lopez-Franco O, MunozGarcia B, Fernandez-Vizarra P, Ortega L, Egido J, Gomez-Guerrero C: Suppressors of cytokine signaling modulate JAK/STAT-mediated cell responses during atherosclerosis. Arterioscler Thromb Vasc Biol 2009;29:525-531.

17 Liang X, He M, Chen T, Liu Y, Tian YL, Wu YL, Zhao Y, Shen Y, Yuan ZY: Multiple roles of SOCS proteins: differential expression of SOCS1 and SOCS3 in atherosclerosis. Int J Mol Med 2013;31:1066-1074.

18 Recio C, Oguiza A, Mallavia B, Lazaro I, Ortiz-Munoz G, Lopez-Franco O, Egido J, Gomez-Guerrero C: Gene delivery of suppressors of cytokine signaling (SOCS) inhibits inflammation and atherosclerosis development in mice. Basic Res Cardiol 2015;110:8.

19 Grothusen C, Schuett H, Hillmer A, Lumpe S, Grote K, Ballmaier M, Bleich A, Glage S, Tietge UJ, Luchtefeld M, Schieffer B: Role of suppressor of cytokine signaling-1 in murine atherosclerosis. PLoS One 2012;7:e51608.

20 Panek CA, Ramos MV, Mejias MP, Abrey-Recalde MJ, Fernandez-Brando RJ, Gori MS, Salamone GV, Palermo MS: Differential expression of the fractalkine chemokine receptor (CX3CR1) in human monocytes during differentiation. Cell Mol Immunol 2015;12:669-680.

21 Feng X, Szulzewsky F, Yerevanian A, Chen Z, Heinzmann D, Rasmussen RD, Alvarez-Garcia V, Kim Y, Wang B, Tamagno I, Zhou H, Li X, Kettenmann H, Ransohoff RM, Hambardzumyan D: Loss of CX3CR1 increases accumulation of inflammatory monocytes and promotes gliomagenesis. Oncotarget 2015;6:15077-15094.

22 Poupel L, Boissonnas A, Hermand P, Dorgham K, Guyon E, Auvynet C, Charles FS, Lesnik P, Deterre P, Combadiere C: Pharmacological inhibition of the chemokine receptor, CX3CR1, reduces atherosclerosis in mice. Arterioscler Thromb Vasc Biol 2013;33:2297-2305.

23 Peters VA, Joesting JJ, Freund GG: IL-1 receptor 2 (IL-1R2) and its role in immune regulation. Brain Behav Immun 2013;32:1-8.

24 Chitu V, Stanley ER: Colony-stimulating factor-1 in immunity and inflammation. Curr Opin Immunol 2006;18:39-48.

25 Pollard JW: Trophic macrophages in development and disease. Nat Rev Immunol 2009;9:259-270.

26 Dai XM, Ryan GR, Hapel AJ, Dominguez MG, Russell RG, Kapp S, Sylvestre V, Stanley ER: Targeted disruption of the mouse colony-stimulating factor 1 receptor gene results in osteopetrosis, mononuclear phagocyte deficiency, increased primitive progenitor cell frequencies, and reproductive defects. Blood 2002;99:111120.

27 Bourette RP, De Sepulveda P, Arnaud S, Dubreuil P, Rottapel R, Mouchiroud G: Suppressor of cytokine signaling 1 interacts with the macrophage colony-stimulating factor receptor and negatively regulates its proliferation signal. J Biol Chem 2001;276:22133-22139.

28 Yona S, Kim KW, Wolf Y, Mildner A, Varol D, Breker M, Strauss-Ayali D, Viukov S, Guilliams M, Misharin A, Hume DA, Perlman H, Malissen B, Zelzer E, Jung S: Fate mapping reveals origins and dynamics of monocytes and tissue macrophages under homeostasis. Immunity 2013;38:79-91.

29 Leblond AL, Klinkert K, Martin K, Turner EC, Kumar AH, Browne T, Caplice NM: Systemic and Cardiac Depletion of M2 Macrophage through CSF-1R Signaling Inhibition Alters Cardiac Function Post Myocardial Infarction. PLoS One 2015;10:e0137515.

30 Babamusta F, Rateri DL, Moorleghen JJ, Howatt DA, Li XA, Daugherty A: Angiotensin II infusion induces sitespecific intra-laminar hemorrhage in macrophage colony-stimulating factor-deficient mice. Atherosclerosis 2006;186:282-290.

31 Shaposhnik Z, Wang X, Lusis AJ: Arterial colony stimulating factor-1 influences atherosclerotic lesions by regulating monocyte migration and apoptosis. J Lipid Res 2010;51:1962-1970.

32 Rajavashisth T, Qiao JH, Tripathi S, Tripathi J, Mishra N, Hua M, Wang XP, Loussararian A, Clinton S, Libby P, Lusis A: Heterozygous osteopetrotic (op) mutation reduces atherosclerosis in LDL receptor- deficient mice. J Clin Invest 1998;101:2702-2710.

33 Yamato K, Tamasawa N, Murakami H, Guan JZ, Tanabe J, Matsui J, Suda T, Yasujima M: Quantitative analysis of apolipoprotein E secretion by human monocyte-derived macrophages in culture. Tohoku J Exp Med 2003;201:47-54.

34 Schneider C, Nobs SP, Kurrer M, Rehrauer H, Thiele C, Kopf M: Induction of the nuclear receptor PPARgamma by the cytokine GM-CSF is critical for the differentiation of fetal monocytes into alveolar macrophages. Nat Immunol 2014;15:1026-1037. 


\section{Cellular Physiology Cell Physiol Biochem 2019;52:336-353 \begin{tabular}{ll|l} 
and Biochemistry & $\begin{array}{l}\text { DOl: 10.33594/000000024 } \\
\text { Published online: 28 February } 2019\end{array}$ & $\begin{array}{l}\text { O } 2019 \text { The Author(s). Published by } \\
\text { Cell Physiol Biochem Press GmbH\&Co. KG }\end{array}$ \\
\cline { 2 - 3 }
\end{tabular} \\ Schuett et al.: SOCS-1-Dependent Gene Regulation}

35 Bouhlel MA, Derudas B, Rigamonti E, Dievart R, Brozek J, Haulon S, Zawadzki C, Jude B, Torpier G, Marx N, Staels B, Chinetti-Gbaguidi G: PPARgamma activation primes human monocytes into alternative M2 macrophages with anti-inflammatory properties. Cell Metab 2007;6:137-143.

36 Scholtysek C, Ipseiz N, Bohm C, Krishnacoumar B, Stenzel M, Czerwinski T, Palumbo-Zerr K, Rothe T, Weidner D, Klej A, Stoll C, Distler J, Tuckermann J, Herrmann M, Fabry B, Goldmann WH, Schett G, Kronke G: NR4A1 Regulates Motility of Osteoclast Precursors and Serves as Target for the Modulation of Systemic Bone Turnover. J Bone Miner Res 2018; DOI:10.1002/jbmr.3533.

37 Sharrocks AD: The ETS-domain transcription factor family. Nat Rev Mol Cell Biol 2001;2:827-837.

38 Duren RP, Boudreaux SP, Conneely OM: Genome Wide Mapping of NR4A Binding Reveals Cooperativity with ETS Factors to Promote Epigenetic Activation of Distal Enhancers in Acute Myeloid Leukemia Cells. PLoS One 2016;11:e0150450.

39 Schweitzer BL, Huang KJ, Kamath MB, Emelyanov AV, Birshtein BK, DeKoter RP: Spi-C has opposing effects to PU.1 on gene expression in progenitor B cells. J Immunol 2006;177:2195-2207.

40 Carlsson R, Thorell K, Liberg D, Leanderson T: SPI-C and STAT6 can cooperate to stimulate IgE germline transcription. Biochem Biophys Res Commun 2006;344:1155-1160.

41 Dickensheets H, Vazquez N, Sheikh F, Gingras S, Murray PJ, Ryan JJ, Donnelly RP: Suppressor of cytokine signaling-1 is an IL-4-inducible gene in macrophages and feedback inhibits IL-4 signaling. Genes Immun 2007;8:21-27.

42 Hansen M, Gerds TA, Nielsen OH, Seidelin JB, Troelsen JT, Olsen J: pcaGoPromoter--an R package for biological and regulatory interpretation of principal components in genome-wide gene expression data. PLoS One 2012;7:e32394.

43 Huang da W, Sherman BT, Lempicki RA: Systematic and integrative analysis of large gene lists using DAVID bioinformatics resources. Nat Protoc 2009;4:44-57.

44 Huang da W, Sherman BT, Lempicki RA: Bioinformatics enrichment tools: paths toward the comprehensive functional analysis of large gene lists. Nucleic Acids Res 2009;37:1-13.

45 Theocharidis A, van Dongen S, Enright AJ, Freeman TC: Network visualization and analysis of gene expression data using BioLayout Express(3D). Nat Protoc 2009;4:1535-1550.

46 Fulton DL, Sundararajan S, Badis G, Hughes TR, Wasserman WW, Roach JC, Sladek R: TFCat: the curated catalog of mouse and human transcription factors. Genome Biol 2009;10:R29.

47 Shannon P, Markiel A, Ozier O, Baliga NS, Wang JT, Ramage D, Amin N, Schwikowski B, Ideker T: Cytoscape: a software environment for integrated models of biomolecular interaction networks. Genome Res 2003;13:2498-2504.

48 Langfelder P, Horvath S: WGCNA: an R package for weighted correlation network analysis. BMC Bioinformatics 2008;9:559. 